\title{
Teacher Beliefs about Students' Use of Cohesion in Writing: What Does the Textual Evidence Reveal?
}

\author{
Zulfiqar Ahmad \\ University of Jeddah
}

\begin{abstract}
Correspondence concerning this article should be addressed to Zulfiqar Ahmad, ELI, University of Jeddah, Asfan, 21589, Jeddah, Saudi Arabia. Email: zulfiqar16c@hotmail.com
\end{abstract}

\begin{abstract}
Despite an extensive research base in the domain of analyses for academic writing, a study of how pedagogic perceptions are revealed in students' actual writing performance is relatively an under-researched area. This study aimed at finding out the relationships between teachers' beliefs and textual evidence in regard to students' use of cohesion in academic writing. Structured questionnaire and open-ended interviews were used to gauge teachers' perceptions about the subject. Cohesion analysis of the samples of students' academic essays was performed and collated with the teachers' perceptions. The results revealed statistically significant correlations between pedagogic perceptions as well as between textual manifestations of cohesion use in the sample texts. Both agreement and disagreement were observed between what teachers believed about students' ability to use cohesion as a text-forming resource and the textual analysis of cohesion. The study proposes a review of pedagogic practices with focus on academic writing literacy as well as a further research initiative with a larger sample to conduct a micro-level analysis of cohesion to be collated with both teachers' and students' beliefs.
\end{abstract}

Keywords: academic writing; cohesion analysis; mixed-methods; teacher perceptions; text analysis

\section{Introduction}

Analyses of students' writing is a common teacher-task across academia, and serves as a basis for making decisions in regard to planning, delivery, and assessment of the writing products (Pery-Woodley, 1991). It is, therefore, crucial that the analyses are premised on a sound framework duly supported by appropriate analytical instruments. Developing an analytical framework is, however, challenged by the intricacies in defining a workable construct for writing (Weigle, 2002). The contemporary notion of academic writing as being situated in the cognitive, socio-cultural, and linguistic paraphernalia (Hyland, 2006) was probably first echoed by White (1985) who proposed analyses of academic writing for either being a textual entity or for explaining the cognitive processes involved in the production or for the contextual and functional properties that make the text a communicative act. This partially explains why writing is considered a difficult skill since the complexity inherent in developing a workable construct poses serious challenges in creating a scientifically reliable analytical framework. Analyses of writing become even more formidable when the construct is put to multidimensional investigation. For instance, a purely linguistic analysis of a text alongside the cognitive processes that helped create it or the contextual factors that led to the composition of a certain text-type could be a hard task for the investigator. Researchers have employed mixed methods and triangulation techniques to overcome the issues of textual analyses based on multiple paradigms. Surveys, interviews, panel discussions, think-aloud protocols, content analysis, and discourse analysis to name a few are being used selectively in a single study to arrive at empirically reliable and valid findings. A huge stock of research with foci on text analysis triangulated by pedagogic and learning experiences in the form of surveys, interviews, think-aloud protocols, etc. on a variety of textual features is available. However, a study of how teachers' beliefs about students' use of a specific discourse feature, for example cohesion, collate with the textual evidence seems to be a relatively under-researched area. Such an investigation can have viable implications for academic writing pedagogy, learning, course design, assessment, and analysis.

"The collection and analysis of language data", which is also the focus of present study, "is a highly specialized 
applied linguistic task, and several sub-disciplines - for example, language testing/assessment, discourse analysis, conversation analysis, and corpus linguistics have been developed to help to conduct the processing of such data" (Dorneyi, 2007 p.19). Such data collection and data analysis complexity can be effectively handled through the use of a mixed-methods approach. As stated earlier, a mixed-approach can be used to enhance the strengths and control the weaknesses of the research methods employed in a single study. This approach in all its forms eliminates researcher bias and limitations associated with certain data collection techniques (Maxwell, 2005). Dorneyi (2007) illustrates this point by suggesting that context-specificity and unrepresentative sampling in qualitative research can be made bias free if the selection of the qualitative participants is based on the results of an initial representative survey. Similarly, in language analysis, for instance, researchers may want to investigate a typical language feature such as the use of cohesive devices in academic essays for its inherent characteristics as well as incidence and frequency. They can use a large sample of language data and then describe or interpret complex matters by simply using numbers to express meaning, and words to express numbers. Since mixed methods have the potential of adding "rigour, breadth, and depth" to the investigation (Denzin \& Lincoln, 1998 p.4), one can expect research findings that are more reliable and valid as they would have been in either quantitative or qualitative research alone. Not only this, data collection and analysis from multiple resources - triangulation - can also increase the generalizability or external validity of a study. This assumes that results obtained from multiple data collection and data analysis tools are likely to be welcomed by audiences with divergent research perspectives.

Multiple sources of data collection are commonly used in large-scale studies (Cheng, et.al., 2007); however, a combination of two to three research instruments such as the surveys, interviews, content analysis, etc. could be suitable for a small-scale research. Interviews and questionnaires are the two most frequently used sources of collecting qualitative data (Dörnyei, 2007). Interviews are arranged to "appraise someone's condition" Arikunto (2013 p.198) by gathering information in regard to his/her perceptions, etc. about the variable under investigation. Block, (2000) in Alshenqeeti, (2014 p.42) argues that the interviews in linguistic research aim "to take research participants 'at their word' ... [that is] to offer a presentation of the data plus content analysis, but no problematization of the data themselves or the respective roles of interviewers and interviewees".

Similarly, questionnaires are a very convenient and time-saving form of data collection from a larger sample (Brown, 2001; Jordan, 1997). According to Brown (2001) and Gillham (2000) face-to-face, group, and online administration of the questionnaires can yield a higher response rate than through other methods of collection such as self-administered where questionnaires are posted to the respondents. One major weakness of questionnaires is that the participants can misinterpret both the open statements and structured/semistructured items. In addition, low turnout of participant response is another threat. Questionnaires are also vulnerable to incomplete responses or misinterpretation of the items (Gillham, 2000).

Analyses of students' writing in academic contexts have been done from multiple perspectives such as the Contrastive Rhetoric (e.g. Conner, 1996; Kaplan, 1966); Systemic Functional Linguistics (e.g. Halliday, 1996; Halliday \& Hasan, 1976; Halliday \& Mathiessen, 2004; Martin, 1992; Eggins, 2004); Genre studies (e.g. Paltridge, 2014; Swales, 1990); English for Academic Purposes (e.g. Hyland, 2006), etc. For an analysis of cohesion, Halliday and Hasan's (1976) analyses are generally regarded as the starting point for any discussion on the subject. Hasan (1984) proposes the use of cohesion analysis to observe the system of cohesive ties that function within the text. These ties are lexico-grammatical resources, which create textual unity and texture by associating elements within the text to each other.

Halliday and Hasan' s (1976) framework, which this study proposes to use for cohesion analysis, identifies Grammatical Cohesion based on Reference, Substitution, Ellipsis, Conjunctions, and Lexical Cohesion based on Reiteration and Collocation as the main cohesion categories with further sub-categorization of each to count 18 cohesive devices in total. "Reference", according to Halliday and Hasan (1976, p.31), is an item that "instead of being interpreted semantically makes reference to something else for interpretation", and is classed as personal, demonstrative, and comparative. A reference device can be endophoric, with referent being situated inside the text, or exophoric, which is present in the context of situation. For a reference device to be cohesive, it must be endophoric, regardless of whether it is cataphoric (referring forward) or anaphoric (referring backward). Substitution is realized in a word or phrase at the 'lexicogrammatical level' Halliday and Hasan (1976, p.89) and "the substitute item has the same structural function as that for which it substitutes" (ibid). There are three types of Substitution: nominal, verbal, and clausal, which are realized through the use of "one, ones, same", 
"do", and "so, not" respectively. Ellipsis, on the other hand, is "substitution by zero" (Halliday \& Hasan, 1976 p.89).Bloor and Bloor (2013, p.99), consider Ellipsis" omission of words, groups, or clauses", that occurs in the same grammatical settings as substitution, and likewise can be "nominal, verbal, and clausal". A Conjunction is a word or phrase that connects clauses or elements of the text and has the potential to create meaningful relationship between them. Halliday and Hassan (1976) categorized Conjunctions as additive, adversative, causal, and temporal, but later Halliday and Matthiessen (2004 p.535) changed their taxonomy to bring these types under the broader category of a "logico-semantic system of the English clause": elaboration, extension, and enhancement.

Lexical cohesion refers to the "cohesive effect of the use of lexical items in discourse where the choice of an item relates to the choices that have gone before" Bloor and Bloor (2013 p. 101). In other words, Lexical cohesion is about the use of content words and sequencing of events to create consistent links between the text and context (Eggins: 2004). Halliday and Hasan's (1976) original classification of Lexical cohesion was based on Reiteration and Collocation. Reiteration included Repetition, Synonym, Superordinates, and General Nouns. Table 1 illustrates Halliday and Hasan's (1976) cohesion categories and sub-categories with examples:

Table 1

Halliday and Hassan's (1976) cohesion categories

\begin{tabular}{|c|c|c|}
\hline Grammatical Cohesion & Type of Tie & Examples \\
\hline \multirow{3}{*}{ Reference } & Personal & $\begin{array}{l}\text { If the buyer wants to know the condition of the property, he has to have another } \\
\text { survey carried out on his own. p. } 47\end{array}$ \\
\hline & Demonstrative & We went to the opera last night. That was our first outing for months. p.60 \\
\hline & Comparative & Most people have the same breakfast every day. p. 80 \\
\hline \multirow{3}{*}{ Substitution } & Nominal & These biscuits are stale. Get some fresh ones. p.92 \\
\hline & Verbal & Does she sing? Yes, she does. p.127 \\
\hline & Clausal & Everyone seems to think he's guilty. If so, no doubt he'll offer to resign. p.134 \\
\hline \multirow{3}{*}{ Ellipsis } & Nominal & The milk couldn’t be used. All was sour. p.155 \\
\hline & Verbal & She intends to come. - She won't. p.190 \\
\hline & Clausal & The car is running very well. - Yes, I had it serviced recently. p. 209 \\
\hline \multirow{4}{*}{ Conjunction } & Additive & And in all this time he met no one. \\
\hline & Adversative & Yet he was hardly aware of being tired. \\
\hline & Causal & So by night time the valley was far below him. \\
\hline & Temporal & Then, as dusk fell, he sat down to rest. p.238-239 \\
\hline Lexical Cohesion & Type of Tie & Examples \\
\hline \multirow{4}{*}{ Reiteration } & Repetition & I turned to the ascent of the peak. The ascent is perfectly easy. \\
\hline & Synonym & I turned to the ascent of the peak. The climb is perfectly easy. \\
\hline & Superordinate & I turned to the ascent of the peak. The task is perfectly easy. \\
\hline & General Noun & I turned to the ascent of the peak. The thing is perfectly easy. p.279 \\
\hline Collocation & Collocation & Why does this little boy wriggle all the time? Girls don't wriggle. p.285 \\
\hline
\end{tabular}

Cohesion from the perspective of a text analysis system has the potential to explain how and why a text is written in a specific way, and why and how a text is interpreted in a certain way. In fact, text interpretation depends on coherence, which is a "mental phenomenon rather than a property of the spoken or written text, or of the social situation» (Gernsbacher \& Givón, 1995 p.1). Text comprehension from this perspective is a negotiation between the writer's cognition and the text on the one hand, and between the text and the reader's mental representation of the writer's product, on the other. This brings in the role of cohesion as a variable of writing quality and text comprehension, which has been supported (e.g. Liu \& Braine, 2005) and refuted (e.g. McNamara, et al., 2010) by various research studies. Studies that consider cohesion to be a determinant of writing quality are based on the premise that cohesion through its co-referential and co-classificatory devices establishes semantic associations between and across clauses, which in turn facilitate a reader's comprehension of the text. Previous research has shown that both local (links between sentences) and global cohesion (links between paragraphs) features account for text quality and coherence (Crossley, et al., 2019 p.173). Modern studies on cohesion especially from 
the Natural Language Processing (NLP) perspective, however, refute this belief. McNamara et al. (2010), for instance, claim that this is true only of low-proficiency readers. High-proficiency readers with advanced-level inference skills for deciphering the implicit meaning do not depend on text-internal clues such as the cohesive devices. For expert readers, cohesion may produce a "reverse cohesion effect" and is, therefore, not crucial to text interpretation (Crossley \&McNamara, 2011 p.174). All things being equal, the role of cohesion in creating text coherence establishes its status as an essential lexico-grammatical resource for creating texture in the text, which is, in fact, a requisite for a text to be defined as such (Halliday \& Hasan, 1976).

Using perceptions to investigate different aspects of language use has been the focus of various studies in applied linguistics research. Harlow and Muyskens (1994) surveyed French and Spanish teachers' perceptions about the use of literature in language teaching. The respondents put literature in the11th position for its usefulness in language teaching. In a study with a similar focus, Yang (2001 p.459) employed questionnaires and interviews to study literature-oriented language teaching classes. The researcher was able to elicit from the participants that engagement with discussing a novel was 'more "substantial” than simply answering grammar questions'. Erdosy (2004) in Ruegg and Sugiyama (2013) applied think-aloud protocols to compare the assessment performance of four raters on a TOEFL exam. Similarly, MacIntyre (2007) in Ruegg and Sugiyama (2013 p.3)conducted think-aloud protocols to find out if the grading scale that was based on an analytic framework proved reliable in assessing writing. The respondents had to speak out about their beliefs about text structure including introduction, body, and conclusion; cohesion and coherence through transitions; and the number of paragraphs in an essay. The results revealed that the respondents (the raters) believed that the grading scale under investigation had the common features they adhered to when "rating writing for organization".

Ahmad (2010) used survey and semi-structured interviews to gauge Egyptian student-teachers problems with cohesion and coherence while composing academic essays. The participants felt that learning to write academically was more challenging than developing other language skills. Vavla and Gokaj's (2013) research in Albania was about learners' beliefs in regard to self-assessment. They reported that assessment was predominantly teacher-led with students having no involvement of any sort. A study by Cheng et al (2015) gathered Chinese students' beliefs about the relationship between assessment tasks and assessment context. The findings revealed that strategic learning and student counseling predicted a positive correlation between the learning-based classroom assessment context, while this association was statistically negative between the performance-based classroom and assessment setting. Agcam and Babanoglu (2016) studied students' perceptions of language assessment practices in Turkey, the types of examinations, types of testing items, and language skills being assessed. Studies by Mellati and Khademi (2018) and Sultana (2019) used semistructured interviews to gauge the assessment literacy level of English as a Foreign Language (EFL) teachers in Iran and Bangladesh respectively, and concluded that the teachers' literacy greatly impacts students' writing development and teachers' pedagogic skills. However, there seems to be a dearth of research in the domain of cohesion analysis, which empirically collates pedagogic perceptions with the textual evidence.

\section{Aims and significance of the study}

The primary aim of this study was to determine the extent to which teachers' perceptions about the use of cohesion in academic writing, as obtained through the structured questionnaires and open-ended interviews, collate with textual manifestations. The study is expected to present an opportunity for a replica study to those interested in collating perceptual data with textual evidence not only in regard to cohesion use, but also from other text-formation sources. The study is also likely to provide some useful insights into the issues relating to writing pedagogy literacy and learners' use of text-forming resources.

\section{Materials and Methods}

\section{Research design}

The research design for this study was based on the notion of homogenous sampling - a type of purposive sampling, because its units share the same characteristics or traits. A homogeneous sample is often chosen when the research question is specific to the characteristics of the particular group of interest, which is subsequently examined in detail (Cresswell \& Plano Clark, 2011). The first step in this regard was to design a survey and a 
set of open-ended questions for the interview. The survey included eight structured items created on the Likert Scale to elicit teachers' beliefs about students' use of cohesion in writing. There were also two open-ended questions to be used for the interview. Next, EFL teachers in the Arab EFL context were asked to complete the survey via online tool SurveyMonkey. Email and social media sites such as the Facebook and LinkedIn were used to reach out to the participants. For interviews $(n=30)$, colleagues and acquaintance at Yanbu English Language Institute (YELI), University of Jeddah, and King Abdulaziz University, Saudi Arabia were polled. However, before the administration of the survey and the interviews, the participants were given a consent form to participate in the study and were assured anonymity and confidentiality. They were free to opt out of the study at any point without any prior notice. The next step was to collect writing samples to triangulate the data obtained from the survey and the interviews, and to ascertain the extent to which these pedagogic beliefs collated with the actual writing performance of the students. The author decided to collect examination scripts, which were assumed to reveal students' actual writing proficiency. For the collection of the sample texts, formal permission was obtained from the coordinator of the undergraduate programme at YELI. As such, academic essays $(\mathrm{n}=30)$ from the midterm and final examinations were collected for this study. Halliday and Hasan's (1976) framework was chosen for a cohesion analysis of the sample texts. The author decided to use Statistical Procedures for the Social Sciences (SPSS) to analyze the data for both the descriptive and inferential statistics. The data collection and analysis procedures are presented below.

\section{Participants}

The participants included teachers in the Arab EFL context who were randomly chosen to complete a survey and attend an open-ended interview, and the Saudi undergraduate students of academic writing who produced the sample texts that were analyzed for cohesion properties to be triangulated with the teachers' beliefs. The author decided to reach out to the wider EFL teaching community for the collection of teacher perceptions through a structured online questionnaire so that responses beyond the Saudi context could be studied. The English language teaching community in Saudi Arabia was composed of the Native English speakers, non-Arab Arabic speakers, and non-native English speakers with qualifications ranging from bachelor's degrees to a $\mathrm{PhD}$. A good number also had CELTA or similar other teaching qualifications. Similarly, they had varying lengths of English language teaching experience. As for the teacher interviews, for the sake of convenient access, 16 teachers from the ELCY, 12 from the English Language Institute, University of Jeddah (my current workplace), and two from the English Language Institute, King Abdul Aziz University, Jeddah were interviewed. Only teachers who had or were teaching academic writing were targeted. This was also compatible with the norms of purposive/homogeneous sampling since the subjects were assumed to be knowledgeable about the topic and shared common features in regard to their professional practice.

The students who wrote the sample essays in an examination setting were all male monolingual students aged 21 to 23 from Saudi Arabia who shared the same culture despite differences in social class or family background. Before starting this undergraduate academic writing course, all had completed two semesters of English language training in the Foundation Year Programme, which trained them in the four language skills. In addition, they had also completed compulsory modules on "Report Writing" and "Communication Skills" at the Associate Diploma level, which lead to their enrolment in the undergraduate programme. After passing the Foundation and the Associate Degree courses over two years, these students, subject to merit qualification with $60 \%$ minimum for English course scores at the Associate Degree level, were enrolled in the undergraduate programme in different subject specialisations, such as Mechanical Technology, Electrical Technology, Chemical Technology, etc. They completed one semester of Academic Writing I module ENG 301 before they were offered Academic Writing II ENG 302. The texts for the present research were collected from midterm or final examination scripts of students of ENG 302. The choice of a purposive or homogeneous sample referred to in the previous section seemed appropriate because these students had gone through the same English language training for more than two and a half years at one institute, were from the same lingual and cultural background, were of basically the same age group, and shared the same academic interests, i.e. to graduate successfully in their respective discipline. 


\section{Instruments}

The subsections below detail the research instruments that were used in the study.

Survey questionnaire. The survey design was developed keeping in view the analytical framework (Halliday \& Hasan, 1976) and pedagogic context to build in greater reliability and validity. As such, eight items were created and coded (Table T-1) to elicit teachers' beliefs about the use of cohesion in academic writing. Survey question 1 (SQ1) and 2 (SQ2) gathered information about the respondents' beliefs about the use of Personal and Demonstrative/Comparative Reference respectively. SQ3 and SQ4 aimed at collecting data about Substitution and Ellipsis while SQ5 and SQ6 measured teachers' opinions about students' use of the Conjunctives. However, the terms "Coordinators" and "Subordinators" were used for the Conjunctives because they were taught as such. Halliday and Hasan (1976) segregate Lexical cohesion as being based on Reiteration and Collocation, and SQ7 was created to collect information about reiteration and SQ8 about Collocation. EFL teachers $(n=112)$ in the Arab context completed the survey on "SurveyMonkey".

Interviews. Interviews as a research instrument are considered a valid and reliable form of obtaining information about a respondent's perceptions (Johnson \& Turner, 2003). Two open-ended questions were designed for the teachers' interviews $(\mathrm{n}=30)$.

1. Do you think Arab EFL students use cohesive devices effectively to create appropriate academic texts? If yes, what strengths and weaknesses have you found in students' use of cohesive devices?

2. What would you suggest to help students make effective use of cohesive devices in academic writing?

Interview question 1 was designed to elicit teachers' beliefs about students' use of cohesive devices in academic writing in regard to their strengths and weaknesses. Interview question 2 was created to measure pedagogic experiences in respect to academic writing and cohesive devices. The interviews were audio recorded, transcribed, colour-coded, and then put to analysis. Recurring themes were grouped and measured for their frequency and percentage to see the prominent trends. Following this procedure, answers to the two interview questions were found and the results were collated with the cohesion analysis of the sample texts.

Cohesion analysis. Cohesion analysis was modeled on Halliday and Hasan's (1976) framework, and premised on measures of accuracy, misuse, and overuse of cohesive devices (CDs). I applied sentence unit (SU) analysis as Halliday and Hasan (1976) employed in the original study. Instances of appropriate, inappropriate (ambiguous), and overused CDs in each SU was marked and coded as belonging to any of the five main cohesion types i.e. Reference, Substitution, Ellipsis, Conjunction, and Lexical cohesion. In addition, cohesive items per SU and the text, as well as the presupposed item, which helped to establish the cohesive link, were also marked and coded. This data was segregated to identify the appropriate, inappropriate, and overused cohesive devices and explain their behaviour in the sample texts. For the purposes of analysis, appropriate cohesive ties were those that manifested clarity of meaning through a co-referential relationship with the presupposed item. Cox et al's (1991) measure was used to analyze inappropriate use, which is for cohesion items with an ambiguous meaning, that are implicit, or are too distant to relate co-referentially with the presupposing item. Based on Gilquin, et al's (2007, p. 322) criteria, items that are used more than three times and could otherwise be substituted by another linguistic entity were considered overused cohesive devices.

\section{Results}

Descriptive statistics on SPSS was run to obtain sum, mean, standard deviation, median, and interquartile range scores, and non-parametric correlation analysis for the survey and the cohesion analysis of the sample texts. Similarly, percentage scores were also obtained to further explain the teachers' perceptions as elicited in the interviews and behaviour of cohesive devices in the sample texts. The subsections below present results for the survey questionnaire, interviews, and cohesion analysis of the sample texts. 


\section{Survey questionnaire (SQ)}

SQ8 "Students can use Collocations appropriately" $(M=3.60 ; S D=.741 ; M d n=4.00 ; I Q R=1)$ revealed the highest level of agreement (64\%), while SQ1 "Students can use Personal Reference appropriately." had the highest proportion of disagreement $(48 \%)(M=2.77 ; S D=.831 ; M d n=3.00 ; I Q R=1)$. Table 2 shows the descriptive statistics for each of the statements of the survey.

Table 2

Descriptive analysis of the survey

\begin{tabular}{llccccc}
\hline & & \multirow{2}{*}{ Survey items } & Code & \multicolumn{3}{c}{ Teachers' Perceptions (N = 112) } \\
\cline { 3 - 7 } & & M & SD & Mdn & IQR & \\
\hline 1 & Students can use Personal Reference appropriately. & SQ1 & 2.77 & .831 & 3.00 & 1 \\
2 & Students can use Demonstrative and Comparative Reference appropriately. & SQ2 & 3.10 & .934 & 3.00 & 2 \\
3 & Students can use Substitution appropriately. & SQ3 & 3.58 & .882 & 4.00 & 1 \\
4 & Students can use Ellipsis (omission of a word, phrase, or clause) appropriately & SQ4 & 3.50 & .971 & 4.00 & 1 \\
5 & Students can use Coordinators appropriately. & SQ5 & 3.31 & .794 & 3.00 & 1 \\
6 & Students can use Subordinators appropriately & SQ6 & 3.47 & .751 & 4.00 & 1 \\
7 & Students can use Reiteration (Repetition, Synonyms, Superordinates, General & SQ7 & 3.27 & .852 & 3.00 & 1 \\
& Words) appropriately. & & & & & \\
8 & Students can use Collocations appropriately. & SQ8 & 3.60 & .741 & 4.00 & 1 \\
\hline
\end{tabular}

\section{Correlation analysis of the survey items}

Spearman rho $\left(r_{s}\right)$ for the teachers' survey revealed that only SQ5 and SQ6, $r_{s}=.679, p<.01$ had a strong positive correlation. Other significant positive associations found ranged from weak to moderate, such as between SQ2 and SQ7, $r_{s}=.195, p<.05$, between SQ1 and SQ3, $r_{s}=.260, p<.01$, between SQ1and SQ5, $r_{s}=.448, p<.01$, and between SQ8 and SQ7, $r_{s}=.515, p<.01$. The results revealed that there were weak, moderate, and strong chances of a perception score increasing, with an increase in the score of the correlating item on the questionnaire.

\section{Results for interview question 1 (IQ1)}

For interview question 1, three variables were identified and therefore, three types of responses were collected. The first type was designed to ascertain the extent to which the teachers thought Arab EFL students were proficient or deficient in the use of cohesive devices in academic essays as well as their strengths and weaknesses in regard to the use of cohesive devices. Table 3 shows that $56.66 \%$ of the 30 respondents thought that the Arab EFL students were unable to make effective use of cohesive devices in their academic texts. However, $43.33 \%$ of the teachers believed that some students could use cohesive devices in their writing.

Table 3

Teachers' response to students' ability to use CDs

\begin{tabular}{lc}
\hline CD Ability of Use & \% (N=30) \\
\hline Deficient & 56.66 \\
Conditional Use & 43.33 \\
\hline
\end{tabular}

Table 4 reveals that teachers could identify only four strengths with 13 responses as opposed to nine areas of weakness receiving 72 responses. The highest score (53.84\%) was found for "Cohesive devices". "Cognition" with the score of $23.07 \%$ and "Arab culture" with the score of $15.38 \%$ were identified as strengths contributing to the use of cohesive devices in academic writing. The lowest in strength category was "Lexical range", which achieved only $7.69 \%$. 
Table 4

Teachers' response to students' strengths in the use of CDs

\begin{tabular}{lc}
\hline CD Strength area & \% (N=13) \\
\hline Grammatical Accuracy & 0 \\
Lexical Range & 7.69 \\
Cohesive Devices & 53.84 \\
Arabic Culture & 15.38 \\
Cognition & 23.07 \\
\hline
\end{tabular}

The scores for weaknesses in the use of cohesive devices as illustrated in Table 5, on the other hand, were more varied and scattered. Four responses scored $10 \%$ or higher while the remaining five responses fell below this scale. The highest percentage was $25 \%$ for "Cohesion" followed by "Language proficiency", "Functional use", and "Grammatical accuracy" at $18.05 \%, 12.5 \%, 11.11 \%$ respectively. Only $8.33 \%$ of the teachers' responses mentioned "Paragraph organization". Quite interestingly, "Lexical range", "Curriculum matters", and "Arab culture" were all at $6.94 \%$. The lowest response was $5.55 \%$ for "Cognition".

Table 5

Teachers' response to reasons for students' weaknesses in the use of CDs

\begin{tabular}{lc}
\hline CD Weakness area & \% (N=72) \\
\hline Grammatical Accuracy & 11.11 \\
Lexical Range & 6.94 \\
Paragraph Organization & 8.33 \\
Cohesive Devices & 25 \\
Curriculum Matters & 6.94 \\
Functional Use & 12.5 \\
Arabic Culture & 6.94 \\
Cognition & 5.55 \\
Language Proficiency & 18.05 \\
\hline
\end{tabular}

\section{Results for interview question 2}

Interview question 2 was generated to measure teachers' beliefs about the role of pedagogy in helping students to make effective use of cohesive devices in academic writing. A total of 75 responses was received from 30 respondents. Table 6 reveals that except for "Lexical base" (4.16\%), all other responses were quite prominent. The highest score (21.33\%) was seen for "Reading" and "Syllabus design" followed by "Teaching" at 20.83\%. Similarly, 19.44\% of the responses mentioned "Practice" and 15.27\% said "Contextual factors".

Table 6

Teacher beliefs about pedagogic effects

\begin{tabular}{lc}
\hline CDs & \% (N=75) \\
\hline Reading & 21.33 \\
Practice & 19.44 \\
Teaching & 20.83 \\
Lexical Base & 4.16 \\
Syllabus Design & 21.33 \\
Contextual Factors & 15.27 \\
\hline
\end{tabular}




\section{Cohesion analysis}

Cohesion analysis $(M=381.20 ; S D=84.076 ; M d n=375.50 ; I Q R=166)$ revealed (Table 7) that the number of words per texts (WPT) was not very consistent across the collected data and there was considerable variations among the number of words used by individual student writers in their essays. A total of 628 Sentence Units (SU) $(M=20.93 ; S D=3.999 ; M d n=21.00 ; I Q R=21.00)$ were obtained in the 30 texts of the corpus. The results demonstrated that since there was not high variation in the number of SUs per text (SUPT), there was the possibility that some students wrote a larger proportion of simple sentences as compared to those who used compound or complex sentence structures. In addition, 1954 Cohesive Devices (CDs) were identified ( $M=65.13$; $S D=17.202 ; M d n=64.50 ; I Q R=28)$ in these student texts. The results indicated that the students used CDs per text (CDPT) with considerable degrees of variance in their essays.

Table 7

Descriptive statistics for the corpus

\begin{tabular}{lccc}
\hline & WPT & SUPT & CDPT \\
\hline Mean & 381.20 & 20.93 & 65.13 \\
Median & 375.50 & 21.00 & 64.50 \\
Std. Deviation & 84.076 & 3.999 & 17.202 \\
IQR & 166 & 6 & 28 \\
\hline
\end{tabular}

Table 8 shows the category distribution of CDs in the corpus. According to the results, the students felt most comfortable when using Lexical cohesion, which was found to be $49.38 \%(\mathrm{n}=965)$ of the overall use of CDs $(\mathrm{n}=$ 1954) in the sample texts. The next category on the list was Reference, which students used in 712 instances in their writing i.e. $36.43 \%$ of the overall category use. Conjunctions $(n=247)$ were found in $12.64 \%$,while Substitution and Ellipsis were only employed on 10 and 20 occasions in the texts, coming in at $1.02 \%$ and .50\% respectively.

Table 8

Category distribution of $C D$ s in students' academic writing

\begin{tabular}{lcc}
\hline CDs & N & \% \\
\hline Reference & 712 & $36.43 \%$ \\
Substitution & 10 & $.50 \%$ \\
Ellipsis & 20 & $1.02 \%$ \\
Conjunction & 247 & $12.64 \%$ \\
Lexical Conjunction & 965 & $49.38 \%$ \\
\hline
\end{tabular}

\section{Non-parametric test for correlation among corpus variables}

Kendall's Tau_b test revealed weak to moderate positive correlations between the three variables of the corpus. Based on the results, WPT showed a weak positive correlation with SUPT $r_{t}=.386, p<0.01$, and a moderate positive correlation with CDPT $r_{t}=.585, p<0.01$. SUPT was weakly and positively correlated with CDPT $r_{t}=.364$, $p<0.01$. The results shown in Table 9 indicated that there was a weak positive linear increase in the number of sentences and a moderate positive increase in cohesive devices in regard to the text length. 
Table 9

Corpus correlations

\begin{tabular}{llccc}
\hline Kendall's tau_b & WPT & SUPT & CDPT \\
\hline \multirow{2}{*}{ WPT } & Correlation Coefficient & 1.000 & $.386^{* * *}$ & $.585^{* * *}$ \\
& Sig. (2-tailed) &. & .004 & .000 \\
\hline \multirow{2}{*}{ SUPT } & Correlation Coefficient & $.386^{* * *}$ & 1.000 & $.364^{* * *}$ \\
& Sig. (2-tailed) & .004 &. & .006 \\
\hline \multirow{2}{*}{ CDPT } & Correlation Coefficient & $.585^{* * *}$ & $.364^{* * *}$ & 1.000 \\
& Sig. (2-tailed) & .000 & .006 &. \\
\hline
\end{tabular}

SPSS was used to compute Kendall's tau-b correlations of WPT and SUPT with the main cohesion categories i.e. Reference (R), Substitution (S), Ellipsis (E), Conjunction (C) and Lexical cohesion (L), and that of these categories with the overall CDPT. The test results showed a significant moderate positive correlation between WPT and $\mathrm{R} r_{t=.} .521, p<.01$, and $\mathrm{L} r_{t=} .453, p<.01$. On the other hand, SUPT showed a significant moderate positive correlation only with $\mathrm{L} r_{t=} .426, p<.01$. There was a strong positive significant relationship between CDPT and total referential devices (TR) $r_{t=} .649, p<.01$ and between CDPT and total Lexical cohesion (TL) $r_{t=.} .625, p<.01$. Among the correlations between CDPT categories, R was weakly but positively correlated with $\mathrm{L} r_{t} . .306, p<$ .05 , S was also weakly but positively correlated with $\mathrm{L} r_{t}=.337, p<.05$, E was weakly but positively correlated with $\mathrm{R} r_{t=} .327, p<.05$, and weakly negatively correlated with $\mathrm{C} r_{t=.} .381, p<.05$. The results showed that there was a moderate increase in the use of $\mathrm{R}$ and $\mathrm{L}$ in relation to increases in the text length. However, increases in sentence length were indicative of the use of a moderately higher number of lexical devices. Increases in the use of referential cohesion indicated moderate increases in the use of Ellipses and Lexical cohesion. Importantly though, the results also revealed that an increase in the CDPT was marked by a high increase in TR and TL as opposed to total conjunction devices (TC), which were widely dispersed over the corpus.

\section{Appropriate and inappropriate use of CDs}

The descriptive statistics results presented in Table 10 showed that the appropriate use (A) of CDs was far more pervasive than the inappropriate (IA) CDs, except for IAR $(M=3.83 ; S D=2.422 ; M d n=4.50 ; I Q R=5)$. Similarly, Kendal's tau revealed that coefficient correlations between appropriate and inappropriate CDs were not statistically significant, except for AR and IAR, $r_{t}=.311, p<.05$, which showed a weak positive association between the two variables, indicating a weak linear increase in IAR with an increase in AR.

Table 10

Correlation analysis of appropriate \& inappropriate CDs

\begin{tabular}{lccccccccccc}
\hline & AR & IAR & AS & IAS & AE & IAE & AC & IAC & AL & IAL \\
\hline Mean & 19.90 & 3.83 & .33 & .00 & .67 & .00 & 7.63 & .60 & 31.40 & .77 \\
Median & 18.50 & 4.50 & .00 & .00 & .00 & .00 & 7.50 & .00 & 32.00 & .00 \\
SD & 8.903 & 2.422 & .661 & .000 & .844 & .000 & 3.690 & 1.248 & 9.633 & 1.813 \\
IQR & 16 & 5 & 1 & 0 & 1 & 0 & 6 & 1 & 15 & 1 \\
Sum & 597 & 115 & 10 & 0 & 20 & 0 & 229 & 18 & 942 & 23 \\
\hline
\end{tabular}

\section{Results for the overuse of CDs in students' writing}

For the present study, the measure of overuse of CDs was an important variable in ascertaining the extent to which cohesion created texture in students' texts. Table 11 reveals that there was a considerable presence of overused (O) CDs in the sample texts. A total of 395 overused items were identified in the corpus of CDs $(\mathrm{n}=1954)$. Lexical cohesion $(M=10.33 ; S D=8.206 ; M d n=10.00 ; I Q R=14)$, with 310 instances, was the most excessively used device. The results indicated that Lexical cohesion was quite consistently distributed across the texts. This was followed by Reference $(M=2.13 ; S D=3.213 ; M d n=.50 ; I Q R=4)$ with 64 items and Conjunction $(M=.70 ; S D=1.055 ; \mathrm{Med}=.00 ; I Q R=1)$ with only 21 devices. The presence of Reference and Conjunction in the texts was more widely scattered compared to Lexical cohesion. Lexical cohesion constituted $15.86 \%$ of the overuse in the corpus, followed by Reference (3.27\%) and Conjunction (1.07\%) respectively. 
Table 11

Descriptive statistics for overuse of CDs

\begin{tabular}{lcccccc}
\hline CDs & M & SD & Mdn & IQR & N & \% of the corpus \\
\hline OR & 2.13 & 3.213 & .50 & 4 & 64 & $3.27 \%$ \\
OC & .70 & 1.055 & .00 & 1 & 21 & $1.07 \%$ \\
OL & 10.33 & 8.206 & 10.00 & 14 & 310 & $15.86 \%$ \\
\hline
\end{tabular}

\section{Correlation analysis for the overused CDs}

Kendal's tau found a moderate positive significant relationship between OR and CDPT $r_{t=} .400, p<.01$ and between OL and CDPT $r_{t=} .448, p<.01$.OR was found to be significant and moderately positively related with both TR $r_{t=.} .519, p<.01$ and OL $r_{t=} .416, p<.01$. OC had a moderate positive significant correlation with TC $r_{t=}$ $.513, p<.01$ whereas OL showed a moderate positive significant relationship with TL $r_{t=} .504, p<.01$ and a weak positive significant correlation with TR $r_{t=} .293, p<.05$. The results indicated that there were moderate chances of an increase in the number of OR and OL when there was an increase in CDPT. Moreover, a corresponding moderate increase in OR, OC, and OL was expected as TR, TC, and TL increased in number. The results also pointed towards a moderate increase in OR with an increase in OL, and a small increase in OL with an increase in TR.

\section{Discussion}

The majority of the teachers disagreed that "Students can use personal reference appropriately." (SQ1) and a slightly smaller proportion stayed neutral. The results seem to both support and contradict the results of analysis for referential cohesion in students' essays. The fact that referential cohesion is the second most commonly used device after lexical cohesion and a high proportion is appropriately used refute teachers' perceptions. Additionally, the empirical evidence that referential cohesion has the highest proportion of inappropriate use and the second highest percentage of overuse in the corpus indicates that students have problems while using reference items as cohesive devices such as the ambiguous referent, wrong pronoun number for the antecedent, placing a pronoun between the noun and verb phrase due to negative transfer, etc. From the overall corpus of 1954 CDs, students employed 36.43\% of referential cohesion, which supports Bae (2001) but contradicts Na's (2011) study where referential cohesion has the highest percentage of use in the texts. Saudi undergraduate students thus seem to be quite comfortable while using reference devices. This seems logical because the appropriate use of Reference (30.55\%) clearly outnumbers the inappropriate use (5.88\%).

The inappropriate use of reference devices, on the other hand, is not very frequent but reveals some very useful information about students' functional use of language in regard to the use of CDs. These results also collate with teachers' perceptions. These figures point out that the students' issues are mainly with the pronominals; however, there are a few challenges in regard to the accurate use of the demonstratives also. The excerpt (i) below taken from a student's essay is an instance of how the demonstrative "those" refers back to "behavioral problems" mentioned in the previous sentence but is inappropriate as it violates the notion of proximity by ignoring nearness to remoteness. Instead, "these" would have been the right choice. This is, however, a prescriptive view of the use of demonstratives that are generally taught in the classroom. From an SFL (Systemic Functional Linguistics) point of view, for instance, the deictically distant "those" can be a valid choice.

i. I think video games cause behavioral problmes in youth more than the small benefits they get. In the following paraghraphs $i$ will write more details about those behavioral problmes and the other side of good effects.

The teacher respondents were almost evenly divided in their agreement and disagreement with "Students can use demonstrative and comparative reference appropriately." (SQ2). A relatively lower percentage was neutral. Teachers' perceptions about the use of article "the" seem justified not only because of its complexity of use but also because of the cultural and L1 influences. The use of the definite article in Arabic is different from that in English, which accounts for sometimes specifying a general noun without any previous mention or placing 
where an omission is needed. One reason seems to be the teaching of "the" as a grammatical item like that of the conjunctives mentioned later in this discussion. Since "the" is notional as a cohesive item, teaching of "the" should be modeled as such.

The pronominal "they" has been excessively used in example (ii) while referring back to "people" and "parents". This may be because the students could not conceive of an alternative syntactic structure where they might have avoided such overuse. Secondly, they appear context bound to use "they" repeatedly as they exhibit repetition of lexical items, which is a highly prominent aspect of these students' rhetorical strategy. The obvious implication is the focus on teaching pronouns explicitly as cohesive devices rather than as grammatical items so that the students could grasp the notion of referential cohesion in context.

ii. Saudi people is known by eating rice by hands but now day they start to eat by using spon and forke and also it changes the way they speak to people. when they are traviling a lot they will start to hear alot of people talking and they may take their accent or the way they speak.

The next two items "Students can use substitution appropriately." (SQ3) and "Students can use ellipsis (omission of a word, phrase, or clause) appropriately" (SQ4) revealed teachers' agreement, which is supported by the textual evidence in regard to the use of substitution and ellipses. The minimal use of both these devices in the corpus is supported by Bae's (2001) study, which had less than 1\% of these devices. Some instances of the use of Substitution and Ellipsis are presented below:

iii. In conclusion, it is right that video games have a lot of bad affects more than the good ones [S1] but $i$ am not saying the parents should not allow them to play at all.

iv. Although some people got their money from their parents, many [E1] worked hard to reach where they are now.

These students seem to be applying some of the fundamental uses of both Substitution and Ellipsis in these examples. They, in fact, save the writer from encoding and decoding repetitive information and lend the text a sort of maturity of expression and style. This aspect is evident in the examples where the substituted or the ellipted item is located in the linguistic context of the text. For instance, in (iii) the proform "one" substitutes "effects", which is in the immediate textual context and creates a relationship of the referent and the presupposed - a mandatory qualification for the cohesive relation to exist. Similarly, (iv) shows how students used nominal and clausal ellipsis to achieve cohesion in their writing.

Items SQ5 and SQ6 "Students can use coordinators appropriately." and "Students can use subordinators appropriately" received a high percentage of agreement and a slightly lower neutral response from the teachers. This is collated by the results of the analysis and supported by Mahmoud (2014) and Mohamed (2016) who discovered $91 \%$ and $94 \%$ correctly used conjunctions in students' writing respectively.

v. They would pay all their money to get their health back even if they already have everything a normal person would dream of. And this exactly shows why money isn't the reason that can make you happy in your life.

However, the most significant revelation is in the use of the additive "and" which is, in Arabic discourse, reportedly the most frequently occurring conjunctive in its category (Mohamed-Sayidina, 2010). This aspect was also reported in the interviews of teachers for the present study. In fact, Arab students do use "and" in recurring patterns but the use is mostly that of a coordinator, and as Halliday and Hasan (1976 p.233) suggest, it is "structural rather than conjunctive". It can, however, be used as an additive device when "the 'and' relation operates conjunctively, between sentences, to give cohesion to a text - or rather to create text, by cohering one sentence to another - it is restricted to just a pair of sentences (Halliday \& Hasan, 1976 p.234). This restriction on the use of "and" as an additive conjunctive has serious implications for future research on cohesion, and calls for empirical distinction between the structural and conjunctive use of "and". The teachers refer to the limited range of cohesive devices the Arab students use in their writing; for instance, one teacher reported: "They only use the simple cohesive devices; they are 'and' and 'but'. But when it comes to complex and complicated cohesive devices such as 'however, in addition, furthermore, or in contrast', they don't." Students' texts reveal a limited range 
of the use of cohesive devices, as referred to earlier. In addition, some teachers point out that Arab students make frequent use of only those CDs which are common in both languages such as the additive "and", "for example", the adversative "but", the causal "because", the temporal "first", "secondly", etc., which is supported by the results of the text analysis. Example (vi) highlights an error of form since the student could not structure the proper conjunctive "on the other side/hand" - a problem also noted by one of the teachers responding to an interview question for the present study.

\section{vi. In the other side, youth who are living in cities will definitely lose their identity.}

The last two statements "Students can use reiteration (repetition, synonyms, superordinates, general nouns) devices appropriately." (SQ7) and "Students can use collocations appropriately." (SQ8) aimed to measure teachers' opinions about lexical cohesion. Most of the teachers agreed with both the ideas while a relatively smaller number remained neutral. These perceptions contradict results of lexical cohesion analysis of students' writing that reveal a very high proportion of repetition of the same item as compared to other devices for reiteration such as synonyms, superordinates, and general words. Similarly, a very low percentage of collocations is observed in students' essays. A lack of the use of lexical cohesion, especially the excessive dependence on repeating the same lexical item points to needed changes in writing curriculum and pedagogy. These results are consistent with most research findings on lexical cohesion in EFL contexts, especially in Arab contexts (Abdul Rahman, 2013; Khalil, 1989; Liu \& Braine, 2005; McGee, 2009). This is also supported by the teacher participants in their response to interview and questionnaire items where they agreed on students' ability to use repetition (L1) and inability to use Collocation (L5). The results of appropriate lexical cohesion, however, contradict Berzlánovich (2008), who found a higher frequency of errors in lexical devices. Example (vii) illustrates the use of collocations while (viii)is a typical instance of L1 transfer. Unlike the English (adjective + noun) structure, Arabic follows the (noun + adjective) pattern, and this is repeatedly reflected in students' writing; hence, expressions such as "identity culture" and "styles life" are common.

vii. And argue that there is too much testing in YIC. Although some students oppose this argument, I agree there is too much testing in YIC.

viii. Now a days technology had become one of youth needs which helps them to lose their identity culture as it connect them with the open world and give them many ways and styles life.

A slightly higher percentage of the teachers believed that the students do not use cohesive devices effectively to produce academic texts and so a higher proportion of weaknesses in the use of cohesion is identified compared with the strengths. This is in line with the general notion about Arab EFL students' writing proficiency. Some students have been reported to make use of their cognition while using CDs. As one respondent observed: "But most of the time their memory works for them like they may memorize how to use that cohesive device but if just try to change the context they lose that memory and they may commit some mistakes". On the other hand, some teachers suggested that the problem is not with CDs but with vocabulary: "The ideas are stuck in their heads because they can't formulate them in English". This implies that the students are challenged when they have to organize a text using CDs. They seem to have the ideas but cannot express themselves because of the limited lexical range. The texts unveil that they mostly write around the topic, repeat phrases before the content, and start giving examples using "for example/instance". They repeat ideas more than once, either to highlight the importance of the idea, to convince the reader, or simply because they do not have suitable vocabulary to help them formulate their ideas. Some teachers argued that background schooling is responsible for writing weaknesses including the CDs: "I think the Arab students are not trained from the beginning to organize the building blocks in an orderly manner and construct an argument in a cohesive and coherent way".

The teachers were also requested to suggest measures for improvement in the use of cohesive devices in academic writing. The highest percentage felt that reading is the most crucial missing link that impedes the effective use of CDs in students' writing. This is also evident in the limited lexical range shown by the high frequency of repetition of the same lexical item in students' essays. One respondent observed: "I think reading - both intensive and extensive- of the authentic text of the written material will help them to imbibe the true structure of the language". A similar comment further substantiated the need for developing reading habits among Arab EFL students: "To remedy this issue, they need to read more in English because reading in English enriches the vocabulary and also exposes them to styles of writing". A similar percentage also called for curricular changes to 
help the students make better use of CDs: "So there is a gap between the course expectations and the students' level. I haven't seen a single course and a single part of the syllabus which focuses specifically on cohesive devices". The curriculum should be sensitive to the fact that once students reach the university level, they need to write a lot. The writing course design should explicitly provide instruction on text-forming resources such as cohesion. It is part of writing. So, if in general, the elements that are specific to aspects of writing are not being taken care of, writing as an academic and language skill is also not being taken care of

The teachers also mentioned "practice" and "pedagogy" as important variables in this context. For instance, the following comments illustrates this point: "So why don't we teach students these cohesive devices explicitly giving them ample examples, because most of them they know them." and "The more they practice, the more chances are there that they become proficient writers." First, there is a need to train the students how to write a cohesive paragraph. They should be made to understand that cohesion is semantic not structural. In this context, focusing on language universals can prove useful. Cohesion, in academic contexts, should be taught in relation to domains such as the humanities adopting a genre-based approach, which trains students to adopt appropriate register for the target texts, thereby facilitating the appropriate use of CDs. There is also the need to focus on suprasentential i.e. discourse features and the flow of thoughts and ideas.

A good number of teachers also refer to the contextual factors that can be counted upon such as revamping the examination system, and student placement in writing courses should be level appropriate. Students should be motivated to write. More research into writing problems is needed to identify areas of improvement. There is also need for writing centers so that EFL support systems could be made effectively functional. When we empower students in the class, we give them the power to express themselves, to defend their ideas.

\section{Conclusion}

The results of the questionnaires and interviews revealed some significant trends regarding teachers' beliefs about the teaching and learning of academic writing in Arab EFL contexts. There were statements showing that they agreed on some issues; however, they mostly disagreed. Similarly, data from the text analysis confirms as well as contradicts these perceptions. This reflects the purely academic orientation of the study, which involves an objective enquiry into the state of things that relate to academic teaching in an EFL context.

The study is not without its limitations though. The fact that the sample was collected from a small EFL population in the Arab academic setting assigns limited generalizability to the study. The study did not include students' perceptions, which could have provided a peek into other dimensions of perceptual understanding in regard to textual formation and analysis. Owing to the paucity of space, the study did not focus on the analysis of individual cohesive items that otherwise could have provided a micro-level analysis of the cohesive system in the texts. Nevertheless, the study is expected to be useful in the sense that it can motivate further research to fill in the aforementioned gaps.

\section{References}

Abdul Rahman, Z. A. (2013). The use of cohesive devices in descriptive writing by Omani student-teachers. SAGE Open, 3(4), 1-10. https://doi.org/10.1177/2158244013506715

Agcam, R., \& Babanoglu, M. P. (2016). Students' perceptions of language testing and assessment in higher education. ÜniversiteparkBülten, 5(1-2), 66-77. https://doi.org/10.22521/unibulletin.2016.512.6

Ahmed, A. H. (2010). Students' problems with cohesion and coherence in EFL essay writing in Egypt: Different perspectives. Literacy Information and Computer Education Journal, 1(4), 211-221.

Alshenqeeti, H. (2014). Interviewing as a data collection method: A critical review. English Linguistics Research, 3(1), 39-45. https://doi.org/10.5430/elr.v3n1p39

Arikunto, S. (2013). Prosedur penelitian [Research Procedure]. Jakarta, Indonesia: RinekaCipta.

Bae, J. (2001). Cohesion and coherence in children's written English: Immersion and English-only classes. Issues in Applied Linguistics, 12(1), 51-88. Retrieved fromhttp://languagetesting.info/articles/store/ialreprintbae. 
pdf.

Berzlánovich, I. (2008). Lexical cohesion and the organization of discourse. Center for Language and Cognition Groningen University of Groningen. Retrieved from http://www.rug.nl/research/clcg/education/berzlanovich. pdf.

Bloor, T., \& Bloor, M. (2013). The functional analysis of English. New York, NY: Routledge.

Brown, J. D. (2001). Using surveys in language programs. Cambridge, UK: Harvard University Press.

Cheng, L., Wu, Y., \& Liu, X. (2015). Chinese university students' perceptions of assessment tasks and classroom assessment environment. Language Testing in Asia, 5(13), 1-17. https://doi.org/10.1186/s40468-015-0020-6

Cheng, X., Xu, K., \& Ma, Y. (2007). A Survey of engineering student's use of English language learning strategies. The Journal of Asia TEFL, 4(2), 123-140.

Connor, U. (1996). Contrastive rhetoric: Cross-cultural aspects of second-language writing. Cambridge, UK: Cambridge University Press.

Cox, B. E., Shanahan, T., \& Sulzby, E. (1990). Good and poor elementary readers' use of cohesion in writing. Reading research quarterly, 25, 47-65.

Cox, B. E., Shanahan, T., \& Tinzmann, M. B. (1991). Children's knowledge of organization, cohesion, and voice in written exposition. Research in the Teaching of English, 25(2),179-218.

Creswell, J. W., \& Plano Clark, V. L. (2011). Designing and conducting mixed methods research (2nd ed.). Thousand Oaks, CA: Sage.

Crossley, S. A., \& McNamara, D. S. (2010). Cohesion, coherence, and expert evaluations of writing proficiency. In S. Ohlsson \& R. Catrambone (Eds.), Proceedings of the 32nd Annual Conference of the Cognitive Science Society (pp. 984-989). Austin, TX: Cognitive Science Society.

Crossley, S. A., \& McNamara, D. S. (2011). Understanding expert ratings of essay quality: Coh-Metrix analyses of first and second language writing. International Journal of Continuing Engineering Education and Life Long Learning, 21(2-3), 170-191. https://doi.org/10.1504/IJCEELL.2011.040197

Crossley, S. A., Kyle, K., \& Dascalu, M. (2019). The tool for the automatic analysis of cohesion 2.0: Integrating semantic similarity and text overlap. Behavior Research Methods, 51(1), 14-27. https://doi.org/10.3758/ s13428-018-1142-4.

Denzin, N. K. , \& Lincoln, Y. S. (Eds.). (1998). The landscape of Qualitative research: Theories and issues. Thousand Oaks, CA: Sage.

Dörnyei, Z. (2007). Research methods in Applied Linguistics. Oxford, UK: Oxford University Press.

Eggins, S. (2004). An introduction to systemic functional linguistics. London, UK: Continuum.

Gernsbacher, M. A., \& Givón, T. (Eds.). (1995). Coherence in spontaneous text (Vol. 31). Amsterdam, Netherlands: John Benjamins Publishing.

Gillham, B. (2000). Developing a questionnaire (real world research). London, UK: Continuum.

Gilquin, G., Granger, S. \& Paquot, M. (2007). Learner corpora: The missing link in EAP pedagogy. Journal of English for Academic Purposes, 6, 319-335. https://doi.org/10.1016/j.jeap.2007.09.007

Halliday, M. A. K., \& Hasan, R. (1976). Cohesion in English. London, UK: Longman.

Halliday, M. A. K., \& Mathiessen, C. (2004). An introduction to functional grammar. London, UK: Hodder Arnold.

Harlow, L. L., \& Muyskens, J. M. (1994). Priorities for intermediate-level language instruction. The Modern Language Journal, 78(2), 141-154.

Hasan, R. (1984). Coherence and cohesive harmony. In J. Flood (Ed.), Understanding reading comprehension (pp. 181-219). Delaware, DE: International Reading Association.

Hyland, K. (2006). English for academic purposes: An advanced resource book. London, UK: Routledge.

Johnson, R. B., \& Turner, L. A. (2003). Data collection strategies in mixed methods research. In A. Tashakkor \& C. Teddlie (Eds.), Handbook of mixed methods in social and behavioral research (pp. 297-319). Thousand Oaks, CA: Sage.

Jordan, R.R. (1997). English for academic purposes: A guide and resource book for teachers. Cambridge, UK: Cambridge University Press.

Khalil, A. (1989). A Study of cohesion and coherence in Arab EFL college students' writing. System, 17, 3(89), 359-371.

Liu, M., \& Braine G. (2005). Cohesive features in argumentative writing produced by Chinese undergraduates. System, 33, 623-636. https://doi.org/10.1016/j.system.2005.02.002

Mahmoud, A. (2014). The use of logical connectors by Arab EFL university students: A performance analysis. International Review of Social Sciences and Humanities, 7(1), 176-188.

Martin, J.R. (1992). English text: System and structure. Philadelphia, PE: John Benjamins.

Maxwell, J. A. (Ed.). (2005). Qualitative research design: An interactive approach (2nd ed.). Thousand Oaks, CA: 


\section{ZULFIQAR AHMAD}

Sage

McCutchen, D., \& Perfetti, C. A. (1982). Coherence and connectedness in the development of discourse production. Text-Interdisciplinary Journal for the Study of Discourse, 2(1-3), 113-140.

McGee, I. (2009). Traversing the lexical cohesion minefield. ELT Journal, 63, 212-220. https://doi.org/10.1093/ elt/ccn040

Mellati, M., \& Khademi, M. (2018). Exploring teachers' assessment literacy: Impact on Learners' writing achievements and implications for teacher development. Australian Journal of Teacher Education, 43(6), 1-18. https://doi.org/10.14221/ajte.2018v43n.

Mohamed, N. (2016). Use of conjunctions in argumentative essay by ESL undergraduates. E-Academia Journal UiTMT, 5(1), 1-13.

Mohamed-Sayidina, A. (2010). Transfer of L1 cohesive devices and transition words into L2 academic texts: The case of Arab students. RELC Journal, 41(3), 253-266. https://doi.org/10.1177/0033688210380569

Munoz, A., \& Alvares, M. E. (2007). Students' objectivity and perception of self-assessment in an EFL classroom. The Journal of Asia TEFL, 4(2), 1-25.

Na, Y. H. (2011). Cohesive devices in CMC texts produced by American and Korean EFL writers. Linguistic Research, 28(3), 743-771.

Paltridge, B. (2014). Genre and second language academic writing. Language Teaching, 47(3), 303-318. https:// doi.org/10.1017/S0261444814000068

Pery-Woodley, M. (1991). Writing in L1 and L2: Analyzing and evaluating learners' texts. Language Teaching, 24(2), 68-83. https://doi.org/10.1017/S0261444800006170

Ruegg, R., \& Sugiyama, Y.(2013). Organization of ideas in writing: What are raters sensitive to? Language Testing in Asia, 3(8), 1-12. https://doi.org/10.1186/2229-0443-3-8

Sultana, N. (2019). Language assessment literacy: an uncharted area for the English language teachers in Bangladesh. Language Testing in Asia, 9(1), 2-14. https://doi.org/10.1186/s40468-019-0077-8.

Swales, J.M. (1990). Genre analysis: English in academic and research settings. Cambridge, UK: Cambridge University Press.

Vavla, L., \& Gokaj, R. (2013). Learner's perceptions of assessment and testing in EFL Classrooms in Albania. Mediterranean Journal of Social Sciences, 4(11), 509-515. https://doi.org/10.5901/mjss.2013.v4n11p509

Weigle, S. (2002). Assessing writing. Cambridge, UK: Cambridge University Press.

White, E. M. (1985). Teaching and assessing writing. San Francisco, CA: Jossey-Bass.

Yang, A. (2001). Reading and the non-academic learner: A mystery solved. System, 29(4), 450-460. 